\title{
Information before coronial necropsy: how much should be available?
}

\author{
H Sampson, A Johnson, N Carter, G Rutty
}

\begin{abstract}
Aim-To assess the amount and quality of information supplied before undertaking a coroner's necropsy, based on the supposition that insufficient information may adversely affect the quality of the necropsy.

Methods-For a one year period (947 cases), sudden death reports from the coronial jurisdiction of South Yorkshire (West) were audited to assess the quality of information supplied. Seven specific items of information were sought: age, sex, occupation, date of death, location of the body, position of the body, date of last seeing a general practitioner, and relevant medical history. The results from necropsy and non-necropsy cases were compared.

Results-Only $22.1 \%$ of reports contained all seven items of information. There was no difference between the amount of information supplied in necropsy and non-necropsy cases except about when the general practitioner last saw the deceased. An occupational history was not available in $40.4 \%$ of all deaths.

Conclusions-The quality of information supplied to the pathologist before necropsy may be suboptimal and could affect the thoroughness of the necropsy itself. (f Clin Pathol 1999;52:856-859)
\end{abstract}

Keywords: coroner's necropsy; sudden death; medical history

Before starting any necropsy, the pathologist expects to have some information concerning the deceased. This may be in the form of hospital notes or a police sudden death report. Many police forces have a form for reporting information to the coroner in the event of a sudden death. These forms are not standardised throughout England and Wales but usually have the same basic structure. South Yorkshire Police use a standard form (Gen 18), which is completed in the event of any sudden death and despatched to the coroner (fig 1). The coroner's officer then relays this information to the pathologist before the necropsy. We perceived that the information received before starting a necropsy was in some instances suboptimal. There could be several reasons for this: the relatives are too distressed to talk, an unidentified person has been found, the general practitioner cannot be identified, or a police officer seeks information which may not be relevant to the pathologist's or coroner's requirements. This could adversely affect the quality of the necropsy, ${ }^{1}$ as the pathologist may not have been alerted to, for example, the possibility of an occupational disease or toxin contributing to death. As the function of the necropsy is to provide information, to maximise its effectiveness the prenecropsy information should be of as high a standard as possible. $^{2}$

We reviewed the information given to pathologists and a coroner over a one year period to assess the quality of the prenecropsy information provided. Areas of persistent lack of information were highlighted in order to assist the coroner in modifying the sudden death report form to ensure that all relevant information would be available to those who required it.

\section{Methods}

All sudden death reports forms over a one year period (1996) submitted to the office of HM Coroner for South Yorkshire (West) were assessed. These included cases where a necropsy had not been undertaken because the attending physician (usually a general practitioner) felt able to issue a death certificate when questioned by the coroner's officer. A proforma was compiled to include 16 items of information (table 1). Seven pieces of information were regarded as essential: name, age, date of death or when found dead, where the body was found, occupation, position of the body when found, and relevant medical history. These items were selected after consultation with two pathologists (NC and GNR), our view being that it was vital to have this information before starting the necropsy, though not all of it was specifically requested on the Gen 18 form.

Each case was scored out of 7 , based of whether the seven essential items were included. A report which contained all seven essential items was deemed satisfactory, and if additional useful information was available the report was classified as good. A score of 6 was deemed suboptimal and less than this, insufficient. The results for cases with and without necropsy were compared.

\section{Results}

In all, 947 cases were reviewed. Of these, 656 had had necropsy examinations and 291 had been dealt with by the coroner's office without the need for a necropsy.

The results are shown in table 1 . In all cases, the name was given. The date of birth was almost always available (99.7\%). The date of death was available in $89.7 \%$ of all cases, and in the majority the place where the body was
Accepted for publication 21 July 1999 

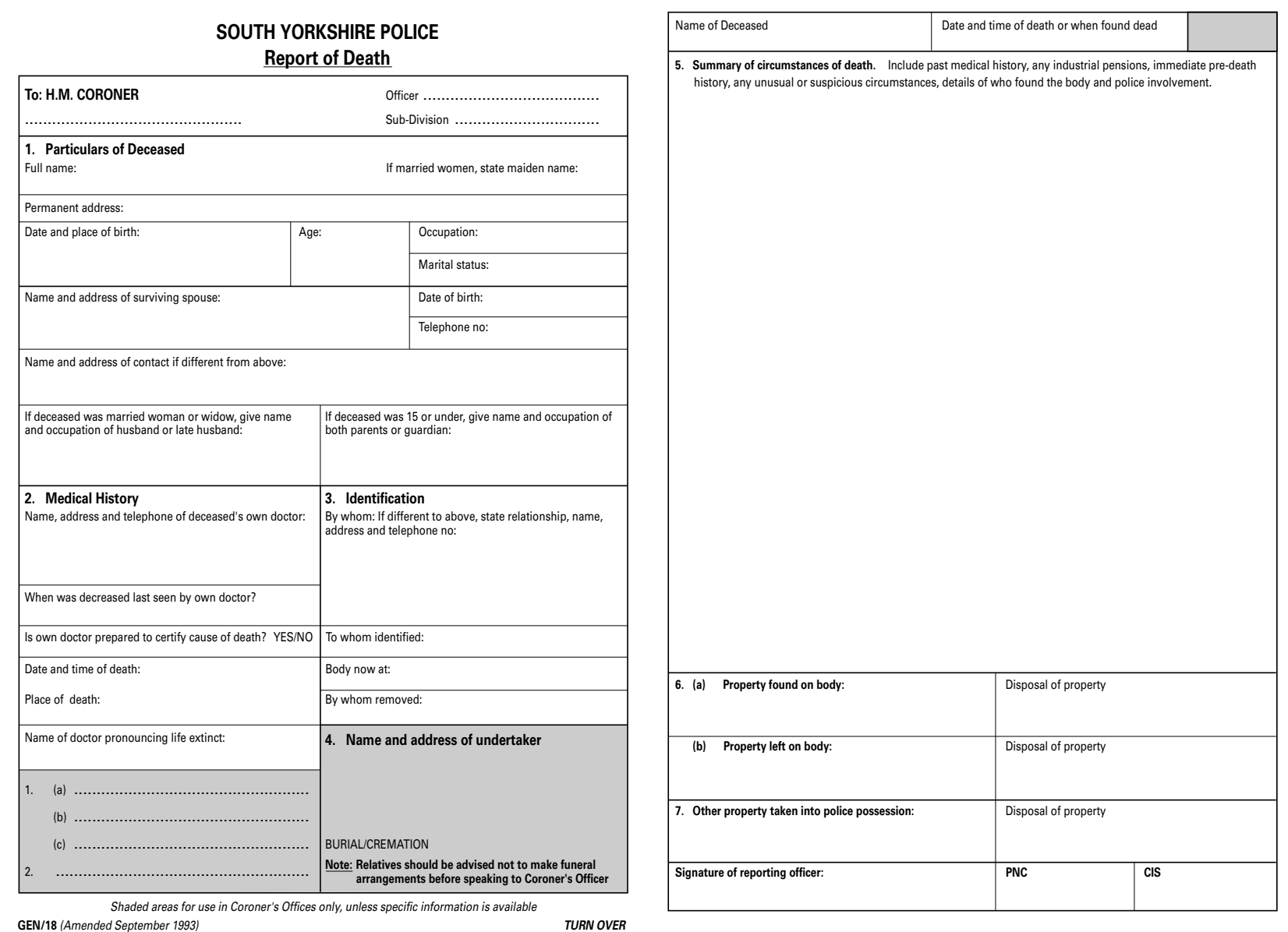

Figure 1 Standard Gen 18 form, South Yorkshire Police (by kind permission of the Chief Constable).

Table 1 Proforma with percentages of data items recorded $(n=947)$

\begin{tabular}{|c|c|c|c|}
\hline \multirow[b]{2}{*}{$\begin{array}{l}\text { Data item } \\
\left(^{*}=\text { essential }\right)\end{array}$} & \multicolumn{3}{|c|}{ Per cent of cases with data item supplied } \\
\hline & $\begin{array}{l}\text { Necropsy } \\
(n=656)\end{array}$ & $\begin{array}{l}\text { Non-necropsy } \\
(n=291)\end{array}$ & $\begin{array}{l}\text { Combined } \\
\text { data }\end{array}$ \\
\hline $\mathrm{Name}^{\star}$ & 100 & 100 & 100 \\
\hline $\mathrm{Age} / \mathrm{DOB}^{\star}$ & 100 & 99.0 & 99.7 \\
\hline Date of death $\star$ & 90.1 & 88.7 & 89.7 \\
\hline Where body found ${ }^{\star}$ & 80.5 & 78.0 & 79.7 \\
\hline Occupation ${ }^{\star}$ & 58.4 & 62.2 & 59.6 \\
\hline Relevant medical history ${ }^{\star}$ & 88.1 & 91.8 & 89.2 \\
\hline Position of body ${ }^{\star}$ & 48.2 & 37.4 & 44.0 \\
\hline Time of death & 66.3 & 74.9 & 69.0 \\
\hline Last seen by GP & 58.1 & 79.7 & 64.7 \\
\hline Industrial disease?/ industrial pension? & 1.4 & 0.3 & 1.1 \\
\hline Last seen alive & 84.1 & 85.9 & 84.7 \\
\hline Who found body? & 88.0 & 93.8 & 89.9 \\
\hline State of house & 4.6 & 5.5 & 4.9 \\
\hline Suspicious circumstances - specify & 60.2 & 57.7 & 59.5 \\
\hline Possible suicide? & 5.3 & 2.1 & 4.3 \\
\hline Drugs & 77.0 & 76.3 & 76.8 \\
\hline
\end{tabular}

DOB, date of birth; GP, general practitioner.

Table 2 Summary of cases reaching various standards defined by seven essential criteria

\begin{tabular}{llcl}
\hline \multirow{4}{*}{ Standard } & \multicolumn{2}{l}{ Per cent of cases reaching specified standard } \\
\cline { 2 - 4 } & $\begin{array}{l}\text { Necropsy cases } \\
(n=656)\end{array}$ & $\begin{array}{l}\text { Non-necropsy cases } \\
(n=291)\end{array}$ & $\begin{array}{l}\text { Combined results } \\
(n=947)\end{array}$ \\
\hline Good (7 items +$)$ & 12.5 & 8.9 & 11.4 \\
Adequate (7 items) & 11.7 & 8.2 & 10.7 \\
Suboptimal (6 items) & 33.1 & 39.5 & 35.1 \\
Insufficient (<6 items) & 42.7 & 3.0 & 42.8 \\
\hline
\end{tabular}

found was noted $(79.7 \%)$. The position of the body when found was poorly documented (48.2\% of necropsy cases and $37.4 \%$ nonnecropsy cases, $44 \%$ combined). The date of last seeing a general practitioner was known in a much higher proportion of non-necropsy cases than necropsy cases $(79.7 \% v 58.1 \%)$.

A medical history was available in a high proportion of all cases (88.1\% necropsy, $91.8 \%$ non-necropsy), even though a necropsy was still needed in the majority. Similarly, the drug history was available in $77.0 \%$ of necropsy cases and $76.3 \%$ of non-necropsy cases.

The occupation was not available in $40.4 \%$ of all cases. There was a common tendency to write "retired" in the report space reserved for noting occupation. It was very rare to receive any information regarding industrial disease ( $1.1 \%$ combined) despite the region's previous industrial activities of steel manufacture, cutlery production, and coal mining.

Overall, taking into account the items deemed essential to a Gen 18 report, only $22.1 \%$ were found to be adequate or good (table 2). Many of the reports contained information irrelevant to the pathologist, at the expense of essential data. Some reports were several pages long, from which the relevant facts could eventually be determined only with difficulty. 


\section{Discussion}

This study confirmed our perception that a relatively small number of reports could be classified as satisfactory, as determined by the seven essential criteria deemed necessary before necropsy. The single piece of essential information most often lacking was an occupational history. We regard this as vital to ensure that appropriate samples are retained at necropsy examination, in compliance with section 9 of the Coroner's Rules 1984, ${ }^{3}$ which require appropriate investigation of the cause of death and any causative factors which may be related to it. In an industrial area such as South Yorkshire, with a high incidence of occupational lung disease resulting from the steelworking and coal mining industries, a question frequently asked by relatives is "was the death related to his/her work?" If information regarding the occupation is sought after the necropsy, it may no longer be possible to obtain suitable samples for analysis. Information regarding industrial disease and industrial pensions was rare. Given the nature of previous employment in the study area and the high incidence of occupation related disease, it is surprising that the information was not more readily available.

It has been argued that where the pathologist needs to interpret the death in the light of clinical information or circumstantial evidence, this should be done at an inquest and not before. ${ }^{4}$ It seems to us that such an approach could cause unnecessary delay in concluding the case, as well as additional distress to relatives. It is a preferable option to provide a cause of death, where possible, immediately after the necropsy, the findings being interpreted in the light of appropriate information provided before the examination.

Coroners' officers are usually skilled at getting information that may not be available to a police officer at the time of the death. We are not suggesting that police officers deliberately do not ask for this information. People often die outside normal working hours, a death is very traumatic for all concerned, and relatives may not be able to recall information immediately after the death that they subsequently may remember. Pathologists, for the most part, do not work a shift system, which police officers do. A recurring problem is when a sudden death report has been filled in, the police officer then goes off duty for eight hours, during which time the coroner's officer is trying to obtain further information. In addition, the general practitioner, an invaluable source of information, may be unavailable for a variety of reasons.

On reviewing our local form, it seems to us that some parts of it are not as "user friendly" as they might be. There is no standardised national sudden death report form or protocol for an investigating officer attending a sudden death, and there is considerable variation between different police forces. There are generally accepted guidelines which are expressed in other forces as variations of the Gen 18. As far as we can ascertain, no review of their efficacy has been undertaken. A police officer cannot be criticised for not obtaining information if it is not specifically sought on the form and the officer does not realise why a particular piece of information is so important.

The first four of our essential criteria are required in order to answer the basic questions of a coronial inquiry - namely, who the deceased was, and where, when, and how they died. With regard to discovering the position of the deceased when found, this assumes great significance if injuries are found on the body or if there is an unusual and unexplained distribution of hypostatic lividity. This information is not specifically sought on the Gen 18 form in its current state, although in our opinion it should be, for the reason given above. The other nine criteria sought in this study were not deemed essential to the coroner, but are certainly relevant to the coroner's inquiries. If there is a suspicion of suicide, it may be important to know the drug history of the deceased. Was an overdose of tablets taken and what drugs were available to be taken? A subjective assessment of the state of the property where the deceased was found may assist the coroner in matters such as self neglect, mental disorder, or unusual lifestyle. Similarly, it is helpful to have some idea of when the deceased was last seen alive. There may be significant postmortem changes, often with severe decomposition of the body. The pathologist is likely to be asked, "are the changes in the body consistent with him being dead for most of the time since he was last seen?" This can be a very difficult question to answer and any guidelines as to how long the person may have been dead are potentially useful.

It may be difficult to ascertain when the deceased last saw a doctor. It is not unusual for a person not to have attended their general practitioner for many years, or even not to have registered with one at all. Such persons may be reclusive in nature and little information regarding their life may be forthcoming. As such, these persons are most likely to have a necropsy. It is therefore of little surprise that the only major difference between the two groups was information concerning when the deceased last saw their general practitioner, this being more readily available in the non-necropsy group.

Overall, the results indicate that the level of information available before necropsy could be improved. This might be achieved in several ways. One solution may be to design the form such that specific questions are asked. As a result of our present findings, it is likely that our local Gen 18 form will be redesigned in an attempt to eliminate the problems we have encountered in obtaining information. There may be a case for a standardised form to be used throughout England and Wales but this would require considerable cooperation of all coroners and police forces at a national level. It may also be appropriate for this cooperation to be extended to include pathologists who have an immediate practical need for the information and are therefore well placed to indicate what is required on the sudden death report. A standard sudden death report form may be of assistance in compiling more accurate death statistics, and results from one region would be 
directly compared with those from another. It may be appropriate to modify the training of police officers so that they are made aware of what is required for a sudden death report and why. We read some very good reports in this study, but the standard was variable. Better information for, and education of, those persons seeking the information after a death might well reduce some of this variability. In addition, increased cooperation of pathologists, coroners, and police could only be of benefit to the community as a whole.
We thank Mr C P Dorries, HM Coroner for South Yorkshire (West), for his permission to use the case material, Mr S Hooper, HM Coroner for the County of South Yorkshire (East), and $\mathrm{Mr} M$ Hedges, Chief Constable of South Yorkshire Police for their advice. We are grateful for the assistance of Det Supt R Purdy and Chief Inspector C Bell.

1 Reys LL, Santos JC. Importance of information in forensic toxicology. Am f Forens Med Toxicol 1992;13:33-6.

2 McPhee SJ. Maximising the benefits of autopsy for clinicians and families. What needs to be done? Arch Pathol Lab Med 1996;120:743-8.

3 The coroner's rules. London: HMSO, 1984.

4 James DS, Leadbeatter S. The use of personal health information in the coroner's inquiry. $f R$ Coll Physicians Lond 1997;31:509-11. 